\title{
Kinetics and Mechanism of Oxidation of 4-Oxo-4-phenylbutanoic Acid by $N$-Bromoanisamide in Aqueous Acetic Acid Medium
}

\author{
G. A. SEYED DAMEEM* and N. A. MOHAMED FAROOK \\ PG and Research Department of Chemistry \\ Khadir Mohideen College, Adirampattinam-614701, Tamilnadu, India \\ nafarook@hotmail.com
}

Received 29 August 2016/ Accepted 20 September 2016

\begin{abstract}
Kinetics and mechanism of oxidation of 4-oxo-4-phenylbutanoic acid (KA) by $\mathrm{N}$-bromoanisamide (NBAS) in aqueous acetic acid medium have been studied potentiometrically. The reactions exhibit a first order rate dependence each with respect to oxidant, substrate and $\left[\mathrm{H}^{+}\right]$. The reaction rate retarded by the addition of anisamide. The decrease in dielectric constant of the medium increases rate of the reaction. Increase in ionic strength, by the addition of sodium perchlorate has no effect on the rate constant. The effect of temperature on the reaction has been investigated in the temperature range $308-323 \mathrm{~K}$. Based on the kinetic results and the product analysis, a suitable mechanism has been proposed for the reaction of NBAS with 4-oxo-4- phenylbutanoic acid.
\end{abstract}

Keywords: Kinetics, Oxidation, $N$-bromoanisamide, 4-Oxoacids, 3-Benzoylpropionic acid

\section{Introduction}

The kinetic study of oxidation of organic compounds is a useful and powerful method in physical organic chemistry. The role of $N$-halo compounds in this field is very wide. They are being used in kinetics, analytical and organic structural investigation. $N$-Halo compounds have been extensively employed as oxidizing agents for organic substrates ${ }^{1,2}$. In the recent development, $N$-halo compounds are the source of positive halogen and have been exploited as oxidant for a variety of substrates in both acidic and alkaline media. The various $\mathrm{N}$-halo compounds extensively used as reagents in organic chemistry are $\mathrm{N}$ bromophthalimide $^{3}, \mathrm{~N}$-bromoacetamide ${ }^{4}, N$-chloroacetamide ${ }^{5}, N$-chlorobenzenesulphonamide ${ }^{6}$, $N$-bromobenzenesulphonamide ${ }^{7}, N$-chlorobenzamide ${ }^{8}, N$-bromobenzamide $^{9}, N$-chloro- $p$ toluensulphonamide ${ }^{10}, \quad N$-chloronicotinamide ${ }^{11}, N$-chlorosuccinimide ${ }^{12}, N$ bromosaccharin $^{13}, \quad N$-bromo-3,5-dinitrobenzamide ${ }^{14}, \quad N$-chlorosaccharin ${ }^{15}, N$ bromosuccinimide $^{16}$ and $N$-bromoanisamide ${ }^{17}$. Although a lot of works have been reported 
on the oxidation of organic compounds by $N$-halo compounds, it is to be noted that no systematic kinetic investigation on the oxidation of 4-oxo-4-phenylbutanoic acid by $\mathrm{N}$ bromoanisamide has yet been reported in the literature. Here we report the results of the kinetics of the oxidation of 4-oxo-4-phenylbutanoic acid (KA) with $\mathrm{N}$-bromoanisamide (NBAS) in aqueous acetic acid medium in the presence of perchloric acid.

\section{Experimental}

4-Oxo-4-phenylbutanoic acid was purchased from Sigma-Aldrich and used as received. $\mathrm{N}$ bromoanisamide was prepared by the reported method. To prevent photochemical effect, the freshly prepared solution of $\mathrm{N}$-bromoanisamide was stored in brown colored bottle and its strength was checked iodometrically. All the chemicals used were of p.a.grade. Acetic acid (BDH) was first refluxed over chromic acid for $6 \mathrm{~h}$ and then distilled. Perchloric acid (AnalaR) was used as source of hydrogen ions. Sodium perchlorate (Merck) was used to keep the ionic strength constant. Double distilled water was employed in all kinetic runs.

\section{Kinetic measurements}

The reaction was carried out under pseudo-first order condition ([KA] $>>$ [NBAS]). The reaction was followed potentiometrically by setting up a cell made up of the reaction mixture into which the platinum electrode and reference electrode (SCE) were dipped. The emf of the cell was measured periodically using an Equip-Tronic potentiometer, while the reaction mixture was continuously stirred. The temperature of the reaction mixture was maintained at the desired value to an accuracy of $\pm 0.1^{\circ} \mathrm{C}$ by circulating thermostated water in the reaction vessel. The pseudo-first order rate constants computed from the plots of log $\left(\mathrm{E}_{\mathrm{t}}-\mathrm{E}_{\infty}\right)$ against time were reproducible within $\pm 3 \%$.

\section{Results and Discussion}

\section{Stoichiometry and reaction products}

Different sets of reaction mixtures containing different quantities of NBAS and KA at constant $\left[\mathrm{H}^{+}\right]$and ionic strength were reacted for $24 \mathrm{~h}$ at $30{ }^{\circ} \mathrm{C}$ and then analyzed. The remaining NBAS was estimated. The oxidation products were identified as benzoic acid and anisamide. It was confirmed by noting the mixed melting point, chemical methods and TLC techniques. The results are in good agreement with 1:1 stoichiometry.

$$
\begin{aligned}
\mathrm{C}_{6} \mathrm{H}_{5} \mathrm{COCH}_{2} \mathrm{CH}_{2} \mathrm{COOH}+ & \mathrm{CH}_{3} \mathrm{OC}_{6} \mathrm{H}_{4} \mathrm{CONHBr}+5 \mathrm{H}_{2} \mathrm{O} \stackrel{\mathrm{H}^{+}}{\longrightarrow} \\
& \mathrm{C}_{6} \mathrm{H}_{5} \mathrm{COOH}+\mathrm{CH}_{3} \mathrm{OC}_{6} \mathrm{H}_{4} \mathrm{CONH}_{2}+3 \mathrm{CO}_{2}+6 \mathrm{H}_{2}+\mathrm{HBr}
\end{aligned}
$$

The liberated $\mathrm{CO}_{2}$ was confirmed by lime-water test.

\section{Reaction order}

Kinetics of oxidation of KA by NBAS was investigated at several initial concentrations of the reactants in aqueous acetic acid medium under pseudo-first order conditions of [substrate] $>[\mathrm{NBP}]$. At constant $[\mathrm{KA}],\left[\mathrm{HClO}_{4}\right],\left[\mathrm{NaClO}_{4}\right]$ and temperature, plots of $\ln \left(\mathrm{E}_{\mathrm{t}}-\mathrm{E}_{\infty}\right)$ vs. time were linear $(\mathrm{r}>0.989)$ indicating first-order dependence of rate on [NBAS]. Furthermore, the rate constants did not change with change in [NBAS] (Table 1), confirming first-order dependence on $[\mathrm{NBAS}]_{\mathrm{o}}$. Also, the rate data in Table 1 point out that $k_{o b s}$ value increases linearly in a first-order fashion with increase in the initial concentration of KA. A plot of $\log k_{\text {obs }} v s$. $\log$ [KA] was linear $(\mathrm{r}=0.995)$ with slope value is 0.998 (Figure 1). Also the plot of $k_{o b s} v s$. [KA] passed through the origin $(\mathrm{r}=0.997)$, establishing 
the first order dependence of rate on [KA] (Figure 2). The rate increased with increase in $\left[\mathrm{HClO}_{4}\right]($ Table 1$)$ and the plot of $\log k_{\text {obs }} v s . \log \left[\mathrm{H}^{+}\right]_{\text {o }}$ was found to be linear $(\mathrm{r}=0.988)$ showing a first-order dependence on $\left[\mathrm{H}^{+}\right]$. Further, the plot of $k_{o b s} v s .\left[\mathrm{H}^{+}\right]$was linear and passed through the origin, indicating that the oxidation occurred only through the acid dependent path under these conditions.

Table 1. Rate constant for the oxidation of 4-oxo-4-phenylbutanoic acid (KA) by NBAS in aqueous acetic acid medium at $30{ }^{\circ} \mathrm{C}^{\mathrm{a}}$

\begin{tabular}{ccccc}
\hline $10^{3}[\mathrm{KA}], \mathrm{M}$ & $10^{4}[\mathrm{NBAS}], \mathrm{M}$ & $10^{2}\left[\mathrm{H}^{+}\right], \mathrm{M}$ & $10^{4} k_{\mathrm{obs}}{ }^{\mathrm{b}}, \mathrm{s}^{-1}$ & $10^{2} k_{2}^{\mathrm{c}}, \mathrm{M}^{-1} \mathrm{~s}^{-1}$ \\
\hline 2.0 & 1.0 & 0.5 & 1.823 & 9.11 \\
4.0 & 1.0 & 0.5 & 3.642 & 9.10 \\
6.0 & 1.0 & 0.5 & 5.526 & 9.21 \\
8.0 & 1.0 & 0.5 & 7.296 & 9.12 \\
10.0 & 1.0 & 0.5 & 9.110 & 9.11 \\
2.0 & 1.0 & 0.8 & 2.88 & 0.36 \\
2.0 & 1.0 & 1.2 & 4.44 & 0.37 \\
2.0 & 3.0 & 1.4 & 5.04 & 0.36 \\
2.0 & 1.2 & 0.5 & 1.821 & - \\
2.0 & 1.4 & 0.5 & 1.823 & - \\
2.0 & 1.8 & 0.5 & 1.820 & - \\
2.0 & 2.0 & 0.5 & 1.822 & - \\
\hline
\end{tabular}

${ }^{a}$ General conditions: $\left[\mathrm{NaClO}_{4}\right]=0.5 \mathrm{~mol} \mathrm{dm^{-3 }}$, Solvent composition: $50 \%$ Acetic acid $-50 \%$ Water $(v / v) .{ }^{b}$ Estimated from pseudo-first order plots, the error quoted in $k_{I}$ values is the $95 \%$ confidential limit of 'Student t' test. 'Individual $k_{2}$ values estimated as $k_{1} /[\mathrm{KA}]$ or $k_{1} /\left[\mathrm{H}^{+}\right]$

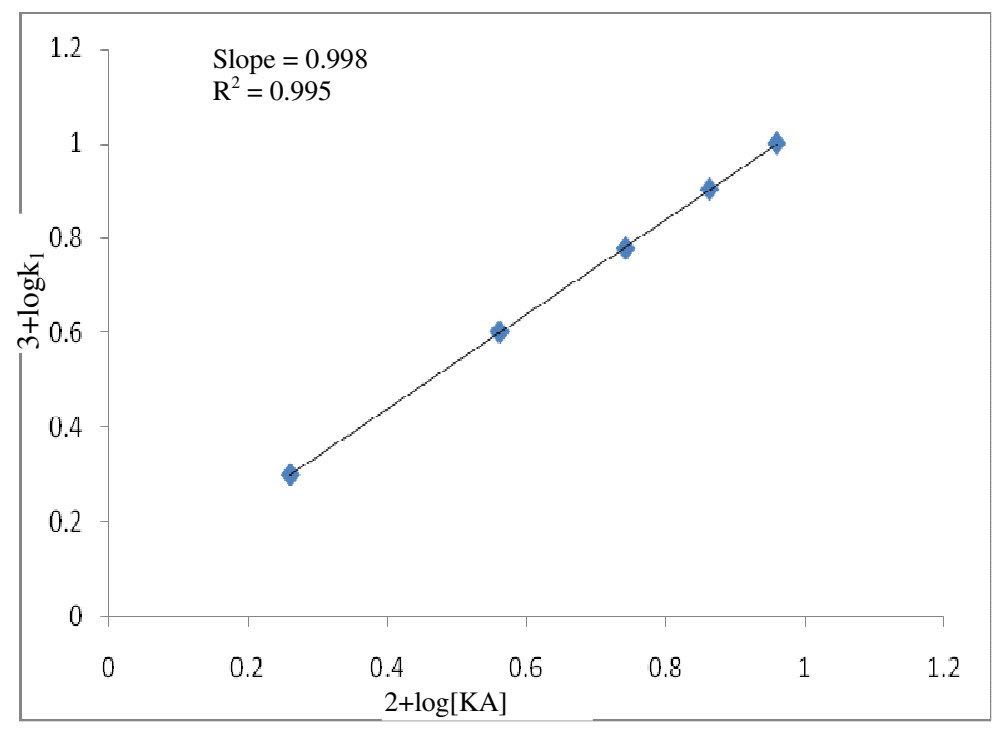

Figure 1. Double logarithmic plot for the oxidation of KA with NBAS 


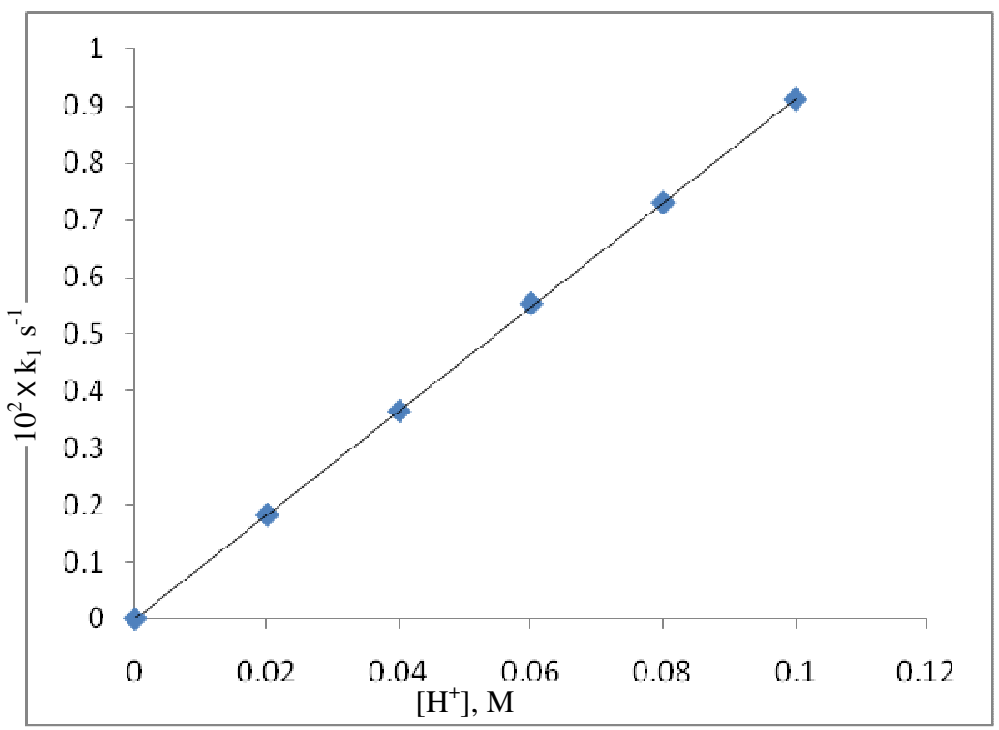

Figure 2. Direct plot of kobs versus [KA] for the oxidation of KA with NBAS

\section{Effect of products}

The effect from adding anisamide was studied, which caused a decrease in the oxidation rate. Thus, retardation of the reaction rate upon addition of anisamide suggests that there is a pre-equilibrium step involving a process in which anisamide is a product.

The effect of dielectric constant in the reaction medium was studied by adding acetic acid (40\%-80\%) in the reaction medium at constant concentrations of other reactants. The reaction rate increased remarkably with the increase in the proportion of acetic acid in the solvent medium. The rate of the reaction is not significantly affected by the change in the ionic strength of the medium brought about by the addition of sodium perchlorate, pointing out the participation of a neutral species as a reactant in the rate-determining step.

The reaction mixture was kept for $24 \mathrm{~h}$ with acrylonitrile in an inert atmosphere. Test for free radical was negative.

The effect of dielectric constant in the reaction medium was studied by adding acetic acid $(50 \%-80 \%)$ in the reaction medium at constant concentrations of other reactants. The reaction rate increased remarkably with the increase in the proportion of acetic acid in the solvent medium. The effect of ionic strength was studied by varying the concentration of $\mathrm{NaClO}_{4}$ in the reaction medium. It was found that the rate of reaction is independent of ionic strength of the medium. The reaction mixture was kept for $24 \mathrm{~h}$ with acrylonitrile in an inert atmosphere. Test for free radical was negative.

\section{The effect of temperature}

The rate of reaction was measured at different temperatures. The activation parameters for the oxidation of KA by NBSA have been evaluated from the slope of the Arrhenius plots.

\section{Mechanism}

It is known that ${ }^{13}$ the probable reactive species of NBSA in acid solution is $\mathrm{H}_{2} \mathrm{O}^{+} \mathrm{Br}$. The reaction is first order in $[\mathrm{NBSA}],[\mathrm{KA}]$ and $\left[\mathrm{H}^{+}\right]$. The reaction rate increases with increase in 
$\left[\mathrm{H}^{+}\right]$at constant ionic strength, showing that the reaction proceeds completely through the acid-catalyzed pathway. The change in the polarity of the medium has a marked effect on the reaction rate. The trend in the rate observed may be due to more than one factor. It may be attributed to the lowering of dielectric constant of the medium which favors reaction involving protonation. Further, the enolization of the keto acid may be catalyzed by acetic acid and this may also contribute to rate enhancement. The plot of $\log \mathrm{k}_{1}$ versus $1 / \mathrm{D}$ is linear $(\mathrm{r}=0.994)$ with positive slope, indicating an interaction between a positive ion and a dipole molecule. This supports the postulation of $\left(\mathrm{H}_{2} \mathrm{O}^{+} \mathrm{Br}\right)$ as the reactive species. The retardation of reaction rate on the addition of saccharin suggests ${ }^{13}$ a pre-equilibrium step involves a process in which saccharin is one of the products.

If this equilibrium is involved in the oxidation process, the retardation should be an inverse function of saccharin concentration, which is borne out by observation that the inverse of the rate constant gives a linear $(r=0.992)$ plot against [Anisamide].

A mechanism has been proposed involving the attack of $\mathrm{H}_{2} \mathrm{O}^{+} \mathrm{Br}$ on the enol form of the substrate (E) in the rate determining step. It is known ${ }^{13}$ that the enolization is proposed to be the necessary step prior to the oxidation of the substrate.

$$
\mathrm{NBSA}+\mathrm{H}_{3} \mathrm{O}^{+} \frac{\mathrm{k}_{1}}{\mathrm{k}_{-1}} \mathrm{H}_{2} \mathrm{O}^{+} \mathrm{Br}+\text { Anisamide }
$$

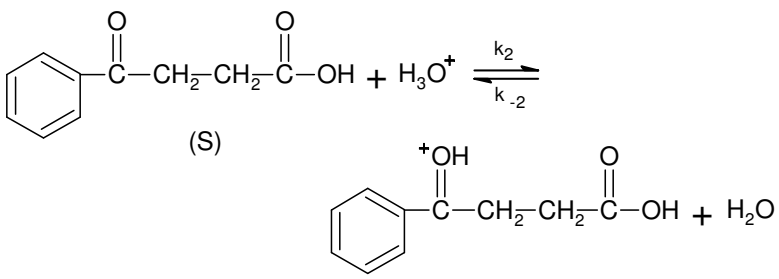

$\left(\mathrm{S}^{+}\right)$

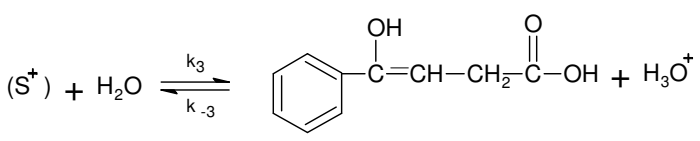

$(\mathrm{E})$<smiles>O=C(O)CC(Br)C(O)(c1ccccc1)c1ccccc1</smiles>

( $\mathrm{F})$

(F)<smiles>C[13CH][13CH]</smiles><smiles>O=C(O)c1ccccc1</smiles>
+ Other products

\section{Scheme 1}


Scheme 1 leads to rate law (7)

$$
\frac{-d[N B A S]}{d t}=\frac{k_{2} k_{3} k_{4}[S]\left[H_{3} O^{+}\right]\left[H_{2} O^{+} B r\right]}{k_{-2} k_{-3} k_{a} \mid[\text { Anisamide }]}
$$

Eq. (7) clearly points out the observed results i.e. first order in [KA], [NBAS], $\left[\mathrm{H}^{+}\right]$and inverse order in [Anisamide] on the rate of the oxidation.

\section{Conclusion}

In the present kinetic study of the 4-oxo-4-phenylbutanoic acid by $\mathrm{N}$-bromoanisamide in aqueous acetic acid medium, a mechanism involving the attack of $\mathrm{H}_{2} \mathrm{O}^{+} \mathrm{Br}$ on the enol form of the substrate. This mechanism is supported by the experimental data such as the reaction stoichiometry, the oxidation products and the activation parameters.

\section{References}

1. Mohamed Farook N A and Seyed Dameem G A, J Chem., 2011, 8(2), 479-482, DOI: $10.1155 / 2011 / 173749$

2. $\quad$ Singh B, Sahai S and Gupta D, Oxidation Commun., 2011, 34(4), 741-745.

3. Mohamed Farook N A, Alhaji N M I, Uduman Mohideen A M, Seyed Dameen G A, Liviu Mitu and Abshana Begam M, J Solution Chem., 2013, 42(6), 1183-1193; DOI: 10.1007/s10953-013-0025-7

4. Singh A K, Srivastava S, Srivastava J and Rahmani, Chinese J Chem., 2008, 26(6), 1057-1067; DOI: 10.1002/cjoc.200890188

5. Mohamed Farook N A and Manochitra S, Chem Sci Trans., 2016, 5(2), 426-430; DOI: $10.7598 /$ cst2016.1244

6. Mahadevappa D S, Sayeed Ahmed M, Made Gowda N M and Thimme Gowda B, Int J Chem Kinet., 2004, 15(8), 775 - 793; DOI: 10.1002/kin.550150807

7. Mohan K, Mahadevappa and Puttaswamy, Chemical Science, 1990, 102(1), 65-72, DOI:10.1007/BF02861572

8. Mohamed Farook N A and Seyed Dameem G A, J Chem., 2011, 8(2), 561-564; DOI: 10.1155/2011/173749

9. Badole M K, Malviya L N, Sariya K S and Siriah V K, Oriental J Chem., 2012, 28, 1433-1436.

10. Rangappa K S, Manjunathaswamy K, Ragahavendra M P and Made Gowde N M, Int J Chem Kinet., 2002, 34, 49; DOI: 10.1002/kin.10011

11. Vivekanandan K and Nambi K, Indian J Chem., 1996, 35B, 1117.

12. Mukaiyama T, Matsuo J, Iida D and Kitagawa H, Chem Lett., 2001, 8, 846.

13. Mohamed Farook N A, Manochitra S and Afroos Banu A, J Solution Chem., 2013, 42(1), 239-250; DOI:10.1007/s10953-012-9942-0

14. Kothari S, Agrawal A and Banerji K K, Indian J Chem., 1986, 25A, 722.

15. Mohamed Farook N A, J Solution Chem., 2007, 36(3), 345-356; DOI: 10.1007/s10953-006-9116-Z

16. Hiran B L, Malkani R K and Rathore N, Kinetics and Catalysis, 2005, 46(3), 334339; DOI: 10.1007/s10975-005-0081-0

17. Malviah L M, Siriah V K and Badole M K, Oriental J Chem., 2013, 29(2), 767-770. 